\title{
Ectopia cordis about a case at Ourossogui regional hospital center
}

\author{
Abdoulaye Diakhate ${ }^{1,2 *}$, Mame D. N. Guèye ${ }^{1}$, Abdou K. Diallo ${ }^{1}$, Mouhamadou Wade ${ }^{1}$, \\ Simon B. Ndour ${ }^{1}$, Daba Diop ${ }^{1}$, Cheikh Dieng ${ }^{2}$, Ameth Mbodji², Mamour Guèye ${ }^{1}$
}

\begin{abstract}
${ }^{1}$ Gynecological and Obstetrical Clinic of The Aristide Le Dantec University Hospital Center, Dakar, Senegal
${ }^{2}$ Maternity of Ourossogui Regional Hospital Center, Dakar, Senegal
\end{abstract}

Received: 04 December 2020

Accepted: 05 January 2021

\section{*Correspondence:}

Dr. Abdoulaye Diakhate,

E-mail: lay.diakhate@gmail.com

Copyright: (c) the author(s), publisher and licensee Medip Academy. This is an open-access article distributed under the terms of the Creative Commons Attribution Non-Commercial License, which permits unrestricted non-commercial use, distribution, and reproduction in any medium, provided the original work is properly cited.

\begin{abstract}
We report in this work, an extremely rare and major case of anterior body wall defects included ectopia cordis define by abnormal location of heart outside of the thorax. This case was diagnosed at the maternity of Ourossogui regional hospital center, in Senegal. Any scan was performed during the pregnancy. Newborn died 10 minutes after birth. Ectopia cordis is related to a possible ventral midline developmental abnormality. It's associated to other midline abnormalities and is a part of pentalogy of Cantrell. An X-linked genetic abnormality.
\end{abstract}

Keywords: Ectopia cordis, Cantrell syndrome, Extrathoracic heart

\section{INTRODUCTION}

Ectopia cordis is a rare and impressive congenital abnormality in which the heart is situated, partially or totally, outside the chest wall. ${ }^{1}$ This condition occurs in rare case of pentalogy of Cantrell. Pentalogy of Cantrell occurs in 5,5 per 1 million liveborn infants. ${ }^{2}$ It's a is a rare genetic disorder characterized by major defects of the sternum, diaphragm and abdominal wall. ${ }^{3}$ Pentalogy of Cantrell affects both male and female and is often fatal. We report one case associated to multiples major malformations. Diagnosed was made at Ourossogui hospital center in north of Senegal.

\section{CASE REPORT}

A 35-year-old pregnant woman was referred to our department at 39 weeks of gestation for excessive uterine height. She was a 7 para without history of fetal anomalies married with second degree of consanguinity with her husband. This pregnancy was the eighth. She had three prenatal consultations. No serology was done during pregnancy, screening for diabetes mellitus neither. Only one obstetrical ultrasound exam was performed at our unit the day of the delivery. Ultrasound's findings were cranial and thoracic wall abnormalities. Fetal heart was outside the chest. The obstetrical examination was marked by an excessive uterine height.

A caesarean section was performed for fetal malformations. The female newborn weighted 3,300 grams. Apgar score was 3 at the first minute, then 5 at the fifth minute.

The newborn has several major morphological abnormalities (Figure 1).

On examination of the head there was a solid tumor covering the totally of forehead. It measured $38 \mathrm{~cm}$. We noted either cleft lip, cleft palate, hypertelorism or arhinia. Ears were low implanted. A tissular cord connected the upper lip to the tumor.

We observed an upper and middle coelostomy. At the chest a large central defect of the anterior thoracic wall was observed with a complete ectopia cordis. The heart was located entirely outside the thoracic cage. No layer of skin covered the heart. Pericardum was absent. Atrial 
morphology was abnormal and heart was beating few minutes.

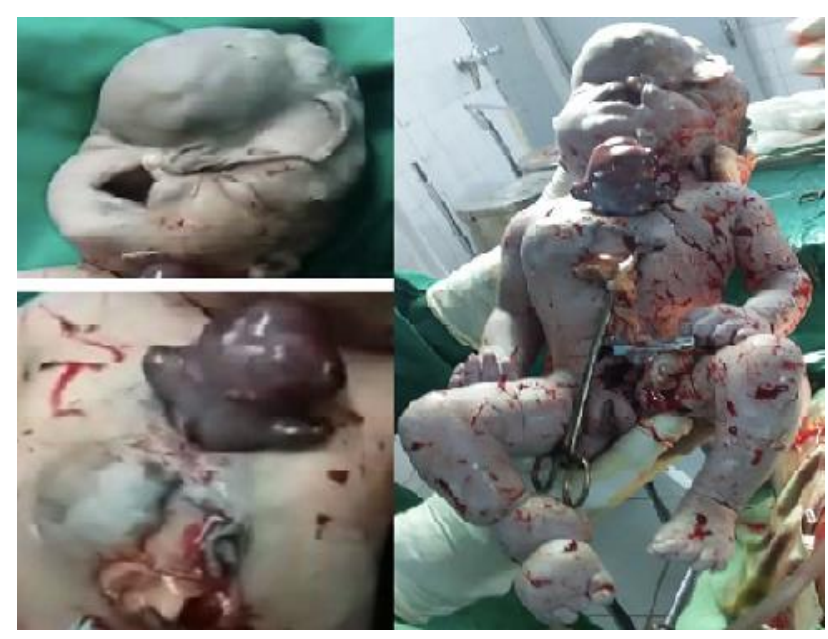

Figure 1: Macroscopic aspect of newborn.

The new born was dead 10 minutes later. Postoperative evolution of the mother.

A large central defect was observed at the abdominal wall. This defect was protected by a thin tissular layer through which we saw the aortic artery and the vena cava.

On right lower limb, an amniotic band sequence was noted with congenital amputation of some phalanx.

\section{DISCUSSION}

Ectopia cordis is a rare and impressive congenital abnormality. His prevalence is estimated at 5.5 to 7.9 per million live births. ${ }^{1}$ Abbot was the first author who defined the "extra thoracic heart".4 Subsequently, the term "ectopia cordis" has been used to describe all anomalies in which the heart was not located inside the thorax. ${ }^{5}$ Four types have been described: cervical (5\%), thoracic $(65 \%)$, abdominal (10\%) and thoracoabdominal (20\%). ${ }^{6}$ The thoracoabdominal form is generally associated with the Cantrell's pentalogy or one of its variants which includes a bifid sternum, a defect of the diaphragm, the anterior abdominal wall and an intracardiac malformation. ${ }^{1}$ Our patient presents a thoraco-abdominal type. In our case, the ectopia cordis was associated with major craniofacial abnormalities and amniotic band sequence. Indeed, although the majority of cases of ectopia cordis are isolated, cases of association with encephalocele, cleft palate or even 18 trisomy have been reported. ${ }^{7}$ A few cases associating ectopia cordis with a reductional limb malformation have been reported in the literature. One example is the case described by Chen et al in 2006, which presented, in addition to ectopia cordis, a hypoplasia of the right upper limb. ${ }^{8}$ Lubala in his study, found no associated intracardiac malformations at autopsy. ${ }^{7}$ With regard to extracardiac malformations, they had observed in one patient a bifid sternum in its lower $2 / 3$ and a defect of the anterior part of the diaphragm. The majority of patients are stillborn or die within hours or days of birth. ${ }^{1}$ Our patient died a few minutes after his born. In a Cameroonian case report, the patient survived until the 7 th month of life without any surgery. ${ }^{6}$ It should be noted that in this case, a layer of skin covered the heart and there were no other associated malformations. In our case, the heart is not covered at all by a serous membrane or skin. Data from the literature show that the heart is completely uncovered in $41 \%$ of patients, it is covered with a serous membrane in $31 \%$ of patients and with a skin covering in $27 \%$ of cases. ${ }^{9}$ The prognosis of ectopia cordis is generally poor. Death commonly occurs immediately after birth, usually owing to associated malformations. Infants with no or mild associated congenital heart disease may survive after successful surgical intervention. ${ }^{10}$ Many authors demonstrated an $\mathrm{X}$ linked inheritance. The genetic disorder is located in a $2,5 \mathrm{Mb}$ interval on Xq25-q26. ${ }^{11}$

\section{CONCLUSION}

Ectopia cordis is a rare and impressive congenital abnormality. It occurs as part of a Cantrell syndrome. His prognosis is generally poor especially in underdeveloped countries.

\section{ACKNOWLEDGMENTS}

Authors would like to present their sincere thanks to all the staff of the Maternity of Ourossogui hospital, Matam, Senegal.

\section{Funding: No funding sources \\ Conflict of interest: None declared \\ Ethical approval: Not required}

\section{REFERENCES}

1. Apte A. Thoraco-Abdominal Ectopia Cordis: A Rare Entity - Case Report and Review of litterature. People's J Sci Res. 2008;1:31-3.

2. Carmi R, Boughman JA. Pentalogy of Cantrell and associated midline anomalies: a possible ventral midline developmental field. Am J Med Genet. 1992;42:90-5.

3. Cantrell JR, Haller JA, Ravitch MM. A syndrome of congenital defects involving the abdominal wall, sternum, diaphragm, pericardium and heart. Surg Gynec Obstet. 1958;107:602-14.

4. Abbott F. Congenital abnormality of sternum and diaphragm; protrusion of the heart in the epigastric region. Tram Pathol Soc London. 1898;69:57-9.

5. Byron F. Ectopia cordis: report of a case with attempted operative correction. J Thorac Surg. 1949; 17:717-22.

6. Tantchou T, Cabral J. Extrathoracic heart in northern Cameroon: a case report. Pan African Med J. 2009;2(8):1-5. 
7. Lubala T, Mutombo A, Katamea T. Ectopia cordis thoracique sporadique : description clinique d'un cas. Pan Afr Med J. 2012;13:62.

8. Chen C, Hsu C, Tzen C. Prenatal diagnosis of pentalogy of Cantrell associated with hypoplasia of the right upper limb and ectrodactyly. Prenat Diagn. 2007;27(1):86-7.

9. Basant K, Sharma C, Sinha D. Ectopia cordis associated with Cantrell's pentalogy. Ann Thorac Med. 2008;3(4):152-3.

10. Kabbani M, Rasheed K, Mallick M. Thoracoabdominal ectopia cordis. Case Rep Ann Saudi Med. 2002;22:5-6.
11. Parvari R, Carmi R, Weissenbach J. Refined genetic mapping of $\mathrm{X}$-linked thoracoabdominal syndrome. (Letter). Am J Med Genet. 1996;61:401-2.

Cite this article as: Diakhate A, Guèye MDN, Diallo AK, Wade M, Ndour SB, Diop D, et al. Ectopia cordis about a case at Ourossogui regional hospital center. Int J Reprod Contracept Obstet Gynecol 2021;10:797-9. 